\title{
ARE MORE FORMAL PERFORMANCE MANAGEMENT SYSTEMS MORE SUCCESSFUL?
}

\author{
Tarmo Kadak \\ Tallinn University of Technology, Estonia \\ Erkki K. Laitinen \\ University of Vaasa, Finland
}

\begin{abstract}
This paper focuses on the levels of formality of performance management systems (PMSs). The objective of the paper is to investigate the impact of the formality of PMS 1) on the key success factors (KFs) of PMS and 2) on the achievement of performance. The formality of PMS is investigated on three different levels: structured and formal PMS, formal PMS, and informal PMS. We define a PMS structured \& formal when it is designed and built upon a well-known existing system structure, such as the BSC. It is regarded as formal when it is formal and designed by the own staff of the firm. PMS is considered informal when the firm does not use any formal system. The paper makes use of the chain framework developed by Kadak and Laitinen (2016) to assess the links between the formality and KFs. The links between the formality and performance are assessed by three different impact measures on performance.

The results implicate that the usage of a structured \& formal PMS has stronger links to KFs of PMS than the usage of the formal in-house designed PMS. Moreover, the usage of a formal PMS leads to stronger links with KFs than using an informal PMS. Formal PMSs make a stronger impact on financial performance than an informal PMS. The same finding can also be observed for achievement of strategic objectives and non-financial performance but the results are not statistically significant due to the small number of informal PMS (5) in the sample. Thus our empirical findings encourage organizations to implement PMSs based on the existing system structures rather than own in-house design and to move from the usage of informal PMSs to formal systems.
\end{abstract}

Keywords: Performance Management Systems, formal PMS, informal PMS, key success factors; performance

JEL code: M410, M2

\section{Introduction and motivation}

Performance Management System (PMS) can be defined as the process of quantifying and improving the performance of an organization. PMS is playing a key role in the management of a modern organization. PMS does not only tell whether an organization is successful, but, if designed and used properly, it also helps an organization implement its strategy and improve its performance (Kaplan and Norton, 1996a; Rompho and Boon-itt, 2012). There is a large body of literature concerned with the design and implementation of PMSs but less studies of their success and failure (Bourne, 2005). If a PMS helps management to improve the performance of an organization, it is successful; otherwise it has failed.

There is however a number of studies on the benefits of PMSs related with the strategy issues of organizations (Kennerley and Neely, 2002; Verweire and Berghe, 2004; Cokins, 2006; Edis, 1995; Kaplan and Norton, 1996a; Braam and Nijssen, 2004). There is also a growing literature addressing the difficulties of PMS implementation (McCunn 1998; Bourne et al. 1999; Schneiderman 1999; Bourne et al., 2000). It is claimed that up to $70 \%$ of performance measurement initiatives fail (McCunn, 1998). Therefore, it is important to investigate what 
kinds of PMS are successful and help the management to improve performance of the organization.

This study focuses on the association between the formality of PMS and success. In the literature there are characteristics of the formal and informal control systems. These are described in an isolated way from each other (Merchant, 1998; Qureshi et al., 2010; Ouchi, 1979; Tucker and Parker, 2013) and in a related way with each other (Abernethy and Chua, 1996; Chenhall et al., 2010; Anderson and Dekker, 2005; Anthony and Govindarajan, 2003; Langfield-Smith and Smith, 2003; Malmi and Brown, 2008 and Sandelin, 2008).

These characteristics stay mostly on the conceptual level and there is not much research about how formal and informal PMS resemble and differ from each other in detail or no quantified advantages of formal over informal PMSs or the contrary and their impacts on the organizational performance. This paper will fulfil these gaps.

The objective of the paper is to investigate the impact of the formality of PMS 1) on the key success factors (KFs) of PMS and 2) on the achievement of performance. We argue that the more formal PMS is, the stronger is its link to success key factors (KFs) of PMS (hypothesis 1) and the stronger is its impact on the achievement of performance within the organization (hypothesis 2). The formality of PMS is investigated on three different levels: structured \& formal PMS, formal PMS, and informal PMS. We define a PMS structured \& formal when it is designed and built upon a well-known existing system structure, such as the BSC. It is regarded as formal when it is formal and designed by the own staff of the firm. PMS is considered informal when the firm does not use any formal system.

When analysing the links between a PMS and success KFs we need a systematic method to assess a PMS and find such KFs. There have been several attempts to develop systematic methods to assess PMSs (Bititci et al., 1997; Najmi et al., 2005; Tangen, 2004; Wettstein and Kueng, 2002; Olsen et al., 2007). Kadak and Laitinen (2016) created a model based on the fourteen KFs constituting the logical chain of PMS. In this paper we will use this assessment model since it provides us with fourteen KFs in a logical and comprehensive framework (Kadak and Laitinen, 2016). Thus, we will assess the links between the formality of PMS and the fourteen success KFs. The links between the formality and performance are assessed by three different impact measures on performance: impact on the achievement of strategic objectives, impact on financial performance, and impact on non-financial performance. The hypotheses of the study will be tested in a small sample (62) of Estonian and Finnish firms.

This paper is organized as follows. In this introductory section the motivation and purpose of the study have been discussed. In the following section, the logical chain of fourteen KFs in PMS is reviewed briefly while the third section introduces the hypotheses of the study. The fourth section deals with the empirical data and statistical methods. In the fifth section the results of empirical study are presented and briefly discussed. Finally, the conclusions are presented in the last section.

\section{Theoretical framework and conceptual model: Chain of KFs}

Kadak and Laitinen (2016) presented a framework to assess the success of a PMS based on a set of fourteen KFs. The idea of this framework was to develop a logical chain of check points where each KF was represented by a check point measured on a scale from 0 to 1 . The authors argued that the strength of this chain is closely associated with the success or the failure of a PMS. It was hypothesized that the stronger the chain, the higher the probability of success in PMS implementation. The strength of the chain was measured by the distribution of the values of check points. The higher the values are in general (sum, average, median), the 
higher the likelihood to success. Empirical evidence strongly supported the proposed framework. In the following text, we will review the fourteen check points only shortly.

1. Clearly expressed mission/vision statement

The mission of the organization should be clear and based on the preferences of stakeholders. In general, mission refers to the reason why an organization exists (Simons, 2000). Mission statement identifies the requirements to attract and maintain shareholders, employees, and customers and to do so in ways that are socially acceptable (Chenhall, 2003). There can be conflicts between different stakeholder groups, because of having different/contradictory preferences. But to enhance the existence of the organization, these conflicts have to overcome to get a clear mission statement. This mission statement creates a vision referring to a picture of the organization in the future.

\section{Clearly expressed strategy, aligned with the mission}

The strategy of the organization should be clearly expressed and aligned with the mission and contextual factors. The strategy briefly describes how an organization intends to fulfil its mission based on its potential, operating environment and considering the stakeholders' interests (Kadak, 2011). The need for an appropriate fit between a company's context, its business strategy and its MCS is an underlying assumption of much of the empirical contingency-style management control research (Chenhall and Langfield-Smith, 1998; Perera, Harrison and Poole, 1997). Thus, strategy is also based on stakeholders' preferences and should be aligned with the mission. It is a way to achieve the corporate mission.

\section{PMS is based on identified causal relationships between CSFs}

PMS should consist of a logical set of CSFs based on the causal relationships in the strategy map. This kind of strategy map ensures that PMS will be connected with the strategy of an organization due to using causal relations which are between different elements of strategy and which may be set into different areas of CSFs (Waal, 2007). Causal links help to integrate various strategic areas with the organization and improve information flow across these strategic areas (Kaplan and Norton, 1996a).

\section{Clearly stated corporate organization-level objectives (CO)}

The organization should clearly express corporate-level objectives, which are derived from the strategy and are congruent with the CSFs in the strategy map. A PMS must be designed and implemented in accordance with a company's business strategy in order to link the strategy to the objectives of functions, groups of people, and individuals (Bierbusse and Siesfeld 1997; Kaplan and Norton 1996b; Nanni, Dixon and Vollman, 1992; Schneiderman, 1999). These objectives make the strategy more specific and concrete for implementation (Kadak, 2011). The objectives should describe concrete activities which lead to the expected final results (Waal, 2007).

5. Organization-level performance measures (PMs) that form a comprehensive set of performance measures

The organization should have a comprehensive set of PMs (that covers all CSFs), measuring the attainment levels of COs in relation to target values, and forming a mutually congruent set aligned with COs. Since each CSF is critical, each of them should be accompanied by PMs making PMS comprehensive (Laitinen, 2004). A clear link between the strategy and performance measures enables PMS to be used effectively (Yu, Perera and Crowe, 2008). The measures have to be defined using objective criteria that make the meaning of each one clear (Globerson, 1985; Neely et al., 2000; Schneiderman, 1999). If targets are unreachable, it results in undesirable behaviour (Beekes, Otley and Ururuka, 2010). 
6. Delegation of organization-level COs as goals to every hierarchical level of the organization

Corporate objectives (COs) should be delegated as goals to every hierarchical level of the organization so that congruence of these goals between and within every hierarchical level is attained. The main purpose of PMS is to implement organizational strategy downward to the departmental level (Daft and Macintosh, 1984). Therefore, in PMS it is essential that COs are translated into operative goals and cascaded the latter down through the organization (Chenhall, 2003).

7. Comprehensive set of PMs at each organizational level

The organization should have a comprehensive set of PMs which measure the attainment level of goals with the help of target values at every hierarchical level of the organization. There must be congruence of PMs so that they are aligned with goals in every hierarchical level of organization. These kinds of PMs are thus used at different levels in organization to evaluate success in achieving goals and thus satisfying the expectations of different stakeholders (Ferreira and Otley, 2009).

8. Identification of key processes (series of activities) critical to attain COs The organization should identify key processes to attain corporate objectives and delegate these processes to attain goals in every hierarchical level of organization. In addition, the organization should have PMs for each key process at every hierarchical level of the organization for input, process, and output control. The key processes should be derived from the measures of the goal and be critical for the achievement of the goal associated with that CSF and measure (Kadak, 2011).

9. PMS is designed and implemented interactively with the users of PMS

The designing and implementation of PMS should be carried out interactively with the users of PMS. For the successful building and implementation of PMS it is necessary to have the involvement and commitment of top-management and members of the organization from the beginning. Performance management and implementation of PMS is very important, and thus this must be top priority (Waal, 2007).

10. PMS is used both interactively and diagnostically to create a dynamic tension

In order to be successful (to improve performance), PMS should be used both interactively and diagnostically to create dynamic tensions for the organization. The organization need to create an appropriate dynamic tension that is likely to stimulate the right mix between compliant behaviour and creative search efforts necessary for organizational success (Simons, 2000).

11. PMS is intensively used by employees in charge

PMS should be intensively used by the staff in charge in order to be successful in improving performance of the organization. This characteristic also considers PMS as an information system and refers partially to the concept of system use that is an important determinant of system success (DeLone and McLean, 2003).

12. PMS is associated with an incentive system

The organization should have an incentive system connected with PMS that motivates employees to perform actions consistent with the goals allocated to them. If PMS is not connected with an appropriate incentive system, it is not motivational to drive employees towards improved performance. PMSs allow the design of goal-congruent incentive systems. Reward and compensation systems are designed to align individual interests with those of the organization (Simons, 1995). 
13. PMS produces valid and reliable information to users in time and in a useful form

The value of PMS is in its ability to provide the users of the systems with valid, reliable, timely, and usable information for their work. These kinds of characteristics consider PMS as an information system and focus on information quality. Information quality can include a large number of attributes such as relevance, understandability, accuracy, conciseness, completeness, currency, timeliness, and usability (DeLone and McLean, 2003). Information quality is a critical determinant of PMS.

\section{PMS is continuously updated}

PMS should be continuously updated for changes in the organization and its surrounding environment. A performance measurement system should include systems for reviewing measures and objectives that make it possible both to adapt the PMS quickly to the changes in the internal and external contexts, and systematically to assess a company's strategy in order to support continuous improvement (Garengo, Biazzo and Bititci, 2005). If PMS is based on an out-of-date model of organization and its organization, its value for staff in improving performance can be questioned. Environments change, organizations change, and so PMSs also need to change in order to sustain their relevance and usefulness (Ferreira and Otley, 2009). Thus, PMS requires continuous improvements and revisions.

\section{Hypotheses of the study}

The variety of different PMSs in practice is very large. However, we can roughly distinguish the usage of three types of PMSs with respect to the structure and formality of systems. Firstly, there are a number of popular and trademarked PMSs (like BSC, Strategy MAP, Five Sigma), which are created by academics and practitioners based on long-time scientific research work. The implementation and success of these well-known systems have been intensively investigated by researchers (Neely, 1999). These systems are usually accompanied by strict formal instructions and recommendations how to structure, implement, use, and update a PMS. When following these pre-tested orders, the management of an organization can be sure that many success KFs of a PMS are met.

Secondly, many organizations have designed and built their own individual PMSs which do not directly follow the structure of any previously existing PMS but are more based on the experiences and preferences of in-house designers. These systems are typically not as formal or structured as the well-known popular PMSs. They do not have any pre-tested instructions or recommendations for structure and design. Therefore, we argue that the formality of these systems is lower and they locate in the hierarchy of formality below the well-known PMSs. Because the well-known popular PMSs are based on long-run constructive scientific work and tested in a large number of organizations, we argue that they are more strongly linked to success KFs and also that they have a stronger impact on organizational performance than PMSs designed by the staff inside the firm.

Thirdly, some firms do not use a formal PMS at all and are only users of an informal PMS. Tannenbaum (1968) argues that organizations without control are impossible. This means that if these firms do not use a formal PMS, they must have an informal management control system. Informal systems may play a very important role within an organization at any stage of development. Before adopting formal control systems, most organizations have some form of mainly informal control (Davila, 2005). Informal control systems are also used by firms living in rapidly changing and highly uncertain environment where formal systems can become a straightjacket. Hence, informal structures are needed to influence the control process to allow flexibility and they are usually used together with formal systems (Chapman, 1998). These systems are often used non-consciously and they are fragmentary, and their 
genesis and updating is accidental. Thus, we argue that the lowest level of the formality hierarchy includes firms which have only informal PMS. Because of their intrinsic intuitive nature, we assume that the links of informal PMSs to success KFs and the impact on performance is the lowest of the three categories of PMS.

Thus, the hierarchy of formality of PMS consists of three layers from informal systems to well-structured and formal well-known systems. We assume that the hierarchy is linked to success KFs in the following way (Hypothesis 1):

H1: The higher the level of formality of a PMS, the stronger the links to the success KFs.

Kadak and Laitinen (2016) concluded that a PMS with stronger links to the chain of KFs has a stronger impact on performance. They measured the impact of PMS on performance by three different types of measures: achievement of organizational strategic objectives, financial performance, and non-financial performance. Their findings showed that the values of all three performance impact measure types were higher when PMSs had a stronger chain of KFs. Therefore, we present the following three hypotheses:

H2a: The higher the formality of a PMS, the higher the achievement level of strategic objectives within the organization.

$\mathrm{H} 2 \mathrm{~b}$ : The higher the formality of a PMS, the higher the impact of the system on financial performance within the organization.

H2c: The higher the formality of a PMS, the higher the impact of the system on non-financial performance within the organization.

\section{Data collecting and statistical methods}

\subsection{Sample}

The empirical data for the study was gathered by Internet questionnaires organized in Estonia and Finland among business sector firms at the same time in spring 2015. The identical questionnaire translated into Estonian and Finnish was used in both countries respectively. In Estonia, the sample of firms was randomly selected from the population of firms employing more than 50 employees. From different sources, email addresses of 500 Estonian firms were randomly selected and an invitation to respond to the survey was sent to the top manager of the firm (CEOs or CFOs). Then, after a couple of follow-up emails, 56 managers had responded to the survey that makes a response rate over $10 \%$. All the responded firms are included in the data of this study.

The address (email) information of Finnish managers was received from Suomen Markkinointi Rekisteri Oy (Finland Marketing Register Ltd) including email addresses of managers from 691 firms from the target industries. In all, 189 email addresses did not operate technically. Then, after follow-up emails, only 50 managers responded to the questionnaire (about 10\% of target industries). From the 50 responded firms, only 5 firms from different industries employed more than 50 employees. Because of the size limit set for the Estonian sample, only these five firms were included in the data of this study. Thus, we have a sample of $62(57+5)$ firms altogether. Because of the small sample size, the results of this pilot study should be considered preliminary.

\subsection{Questionnaire and statistical methods}

The questions of the questionnaire that we use in this study can be classified into three classes: questions associated with formality, KFs, and the impact on performance. The questions are formulated as easy as possible to respond by the manager. First, we roughly 
measured the hierarchy of formality using a closed question with a binary on/off scale (no / yes) on the type of PMS used within the organization. This question based on five items is presented in Appendix 1. We used the three first items to refer to a structured \& formal PMS, the fourth item to refer to a formal PMS, and the fifth item to a purely informal PMS (the management does not use any formal PMS).

Secondly, the fourteen KFs described in the theoretical framework are measured by the questions presented in Appendix 2. In total, the question pattern includes fifteen questions associated with the fourteen KFs. KF 10 is reflected by two different questions referring to the diagnostic and interactive uses of PMS separately. Ten of the questions are based on an on/off scale ( 0 or 1$)$ while five questions are measured on a Likert scale from 1 (do not agree at all) to 7 (agree perfectly). The five questions based on the Likert scale were standardized by deducting unity from the value $\mathrm{V}$ and dividing the difference by $6((\mathrm{~V}-1) / 6)$. In this way, the value was constrained into the range from 0 to 1 .

Thirdly, the success of PMS was measured by three different measures defined on a Likert scale from 1 to 7 (see Appendix 3). The first measure reflects the achievement rate of strategic objectives (STPER). The principal value of PMS is in its ability to support management to achieve strategic objectives. Therefore, the achievement rate is an overall measure of the strategic impact of PMS. The second measure reflects the impact of PMS on non-financial performance of the firm during the last three years as self-assessed by the manager (NFIPER). The third measure refers to the impact of PMS on financial performance during the last three years as self-rated in the same way as the previous measure (FINPER).

The two research hypotheses are tested by simple statistical methods. First, we test the links of the formality to the fifteen questions of KFs (fourteen KFs) using the ANOVA F-test for each question separately (hypothesis 1). We also calculate the sum of the KF chain value and use the same F-test to test whether the samples of three formality hierarchy groups of PMSs are drawn from the same or identical distributions. Secondly, we use the ANOVA F-test to test the impact of PMS on the three types of performance (hypotheses $2 a, 2 b$, and $2 c$ ).

\section{Empirical results}

\subsection{Types of PMSs in the sample organizations}

The questionnaire mapped the type of PMSs used by sample firms with a question consisted of five items. However, using an open question associated with the description of PMS we were able to identify the system in more detail. The responses indicate that eight organizations $(12.9 \%)$ are only using the Balanced Scorecard and six organizations $(9.7 \%)$ only make use of the Strategy MAP while six firms $(9.7 \%)$ report using both the Balanced Scorecard and the Strategy Map. Furthermore, one organization (1.6\%) is using some other well-known PMS (Lean Management), one organization (1.6\%) is using the Balanced Scorecard and some other well-known PMSs (Lean Management and Five Sigma), and one organization (1.6\%) is using the Balanced Scorecard, the Strategy Map and some other well-known PMS. Thus, all 23 organizations $(37.1 \%)$ reported that they were using some combination of the existing wellknown PMSs. These firms are regarded as belonging to the highest formality group in the hierarchy.

The majority of the sample firms reported that they used a PMS that they had designed and constructed by their own staff. The number of these organizations was 34 (54.8\%). These firms belong to the second layer in the present hierarchy of formality. However, only 5 organizations $(8.1 \%)$ reported that they did not use any (formal) PMS. However, these firms answered many of the fifteen questions on KFs positively, implying that they measure and control performance. Therefore, we assume that they are using informal PMSs (Tannenbaum 1968). These five firms are classified into the lowest layer of formality. 


\subsection{Links to KFs (hypothesis 1)}

Table 1 shows the descriptive statistics of the fifteen questions (variables) referring to the fourteen KFs in the logical chain developed by Kadak and Laitinen (2016). For the ten binary (on/off) variables (without $*$ in the table), the mean values directly refer to the percentage of PMSs having "on" response (1). The sum of the positive responses ( 0 to 1 ) to the fifteen questions is for the highest group of formality (users of structured \& formal well-known PMSs) 12.05, for the second group (users of in-house designed formal PMSs) 10.62, and for the lowest group of formality (users of informal PMSs) only 5.73. Thus, the users of informal PMSs show a very weak link to the KFs. For all fifteen questions, they report on average a lower value than the two other groups of organizations.

However, only for four questions out of fifteen variables (IMPUSE, ACTUSE, RESP and ADJ) the average values are lower for the users of structured \& formal PMSs than for those using in-house designed PMSs. When a 2-tailed test (F-test) is applied, only four of the fifteen variables show a higher $\mathrm{p}$-value than $10 \%$. Nine of the variables show a $\mathrm{p}$-value less than or equal to $1 \%$. Thus, in general, these findings give support to the first hypothesis (H1). The differences in the mean values of the fifteen questions between the three groups of organizations are demonstrated in Figure 1.

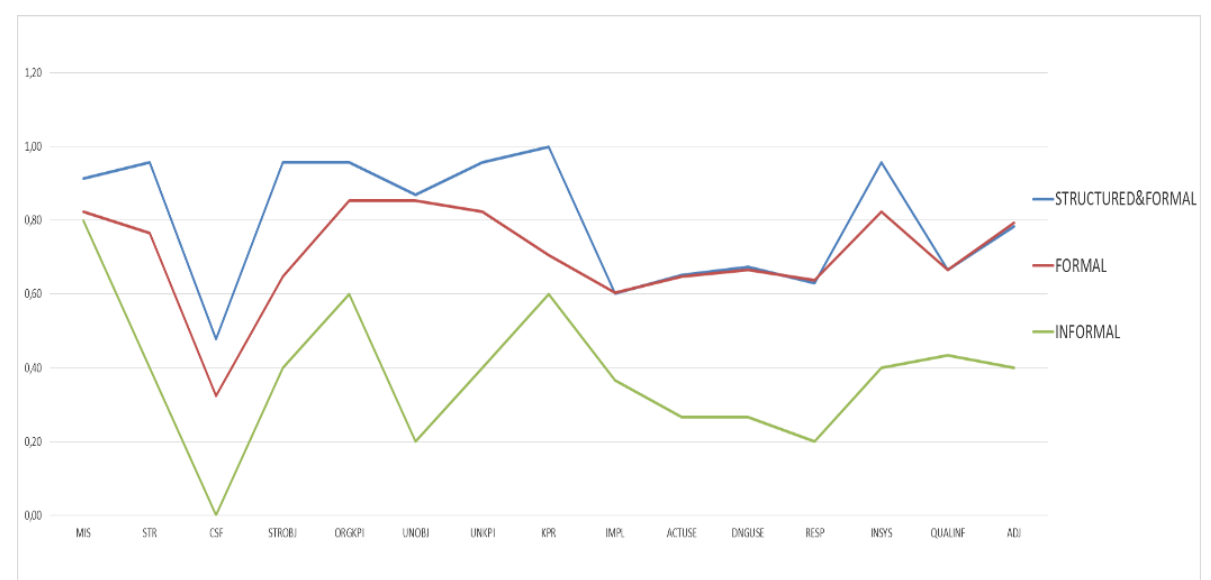

Figure 1. Mean values of KF scores for structured \& formal, formal and informal PMSs

There are, however, differences in the significance of the variables. The least statistical differences between three groups of organizations are found in MIS ( $p=0.6137)$ referring to the existence of mission in an organization. In total, $80 \%$ of the users of informal PMSs and $82 \%$ of those using an in-house designed formal PMS report having a mission while the percentage for the users of structured \& formal well-known PMSs is $91 \%$. The high usage rate of mission inside the informal PMSs is surprising. This $80 \%$ usage rate of all KFs stayed as the highest inside the informal PMSs. The differences in building and designing PMS with the users of the system (IMPUSE) are also relatively small $(\mathrm{p}=0.1696)$.

There are very significant statistical differences found in many of the fifteen variables. Corporate strategy (STR) $(\mathrm{p}=0.0098)$ has been documented in a written form only by $40 \%$ of the informal PMS group and by 77\% of the formal PMS group while the percentage for the structured \& formal PMS group is $96 \%$. The differences are also remarkable related with objectives and measures. Strategic objectives $(\mathrm{STROBJ})(\mathrm{p}=0.0050)$ are set also only by $40 \%$ of the informal PMS group and by $65 \%$ of the formal PMS group while the percentage for the third group is as high as $96 \%$. Moreover, the existence of unit level objectives $(\mathrm{UNOBJ})(\mathrm{p}=0.0011)$ and measures $(\mathrm{UNKPI})(\mathrm{p}=0.0073)$ show significant differences between the groups. 
In addition, a remarkable difference has been found between the groups in having defined key processes $(\mathrm{KPR})(\mathrm{p}=0.0093)$. The users of structured \& formal PMSs have all $(100 \%)$ defined key processes, while the percentages are only $71 \%$ and $60 \%$ for the groups of lower formality PMSs respectively. The differences are also significant in the use and output of PMS. Formal PMSs are used more interactively (ACTUSE) $(p=0.0012)$ and more diagnostically (DNGUSE) $(\mathrm{p}=0.0003)$ than informal PMSs. PMS is interactively used by $65 \%$ and by $67 \%$ of the users of formal PMSs but only by $27 \%$ of the users of informal PMSs. Formal PMSs are also used more intensively (RESP) $(\mathrm{p}=0.0010)$ and they are more associated with an incentive system to motivate employees towards achievement of objectives (INSYS) $(\mathrm{p}=0.0073)$ than informal PMSs.

The PMS literature does not include much quantified empirical evidence about similarities and differences of PMSs on the different formality levels. This research fulfils this gap classifying all fifteen KFs into three equal groups on the basis of the size of the difference in the mean value of every KF between the structural \& formal PMSs and informal PMSs. These differences are graphically presented in Figure 2.

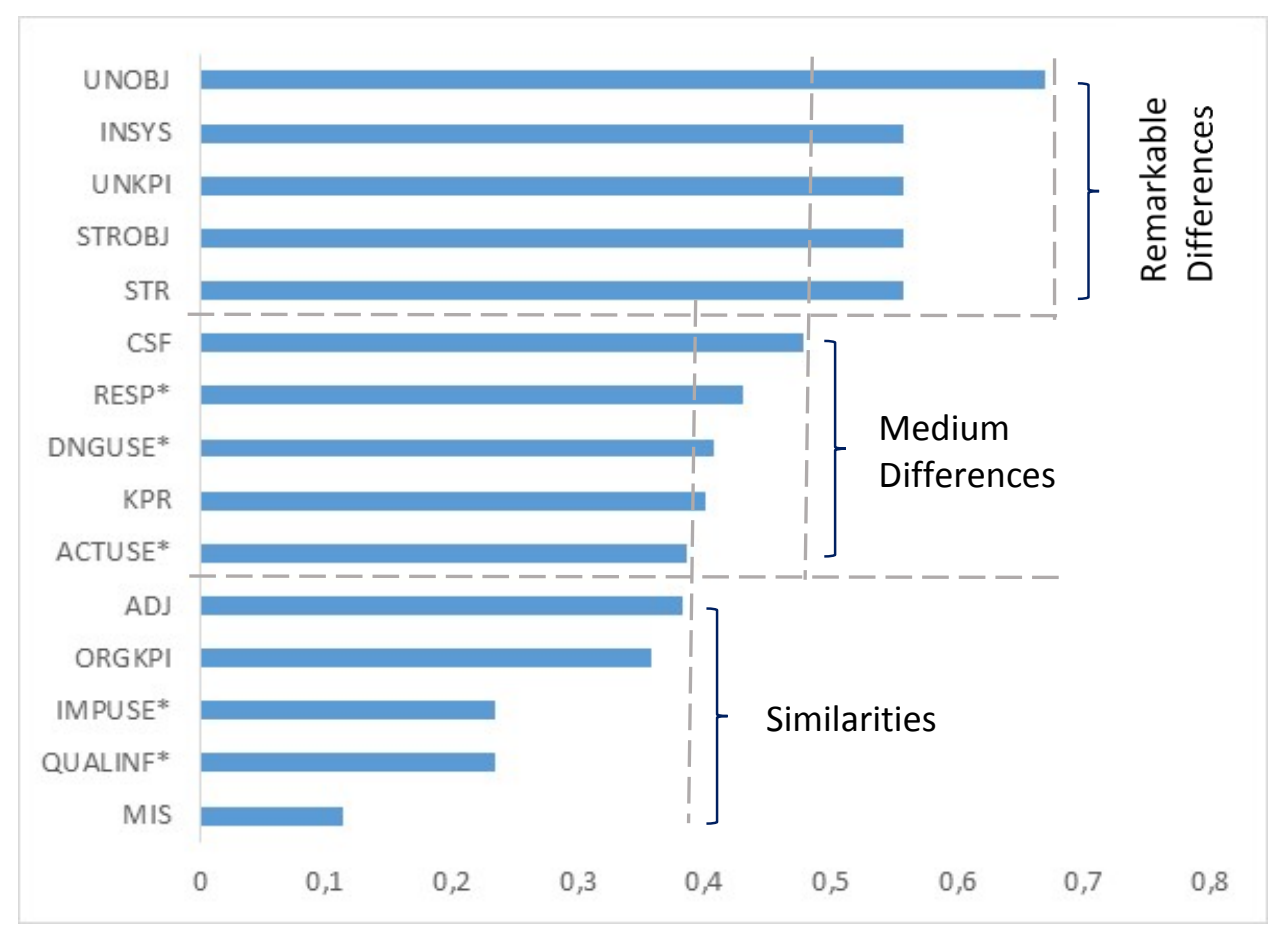

Figure 2. Similarities and differences of structured \& formal and informal PMSs

The structural \& formal and informal PMSs are quite similar with each other with respect to such KFs like MIS, QUALINF, IMPUSE, ORG KPI and ADJ. These similarities indicate that both groups value highly the tails of PMSs, namely the existence of mission and receiving valid, reliable, timely, and usable information from PMS. These groups also see equally the need for systematic updating of PMS when changes in organization or environment are emerged. These results allow us to conclude that the firms using structural and formal PMSs relatively little stress the importance of issues related with information quality which in turn shows to them the direction for improving PMS to increase its success.

The difference in the mean values between the groups is the highest for KFs like UNOBJ, INSYS, UNKPI, STROBJ and STR. This comparison enables us to conclude that the users of structural \& formal PMSs use more strategy translating tools (strategy, organizational and unit level objectives and measures) than the users of informal PMSs. It means that the users of 
structural \& formal PMSs handle the strategy execution in more details and the users of informal PMSs in a more complex way. This evidence can be explained by the fact that wellknown PMSs are designed during long-term research projects and well documented in the textbooks. Therefore, they are more structured and more split by KFs with respect to certain functions including also KFs necessary for successful strategy execution. Furthermore, these structural and formal PMSs are more closely associated with an incentive system than informal PMSs.

The differences between the PMS groups are at a medium level for such KFs as ACTUSE, KPR, DNGUSE, RESP and CSF. If the similarities of PMSs in both formality levels impact equally the success of PMS, then the differences in the strategy issues begin to matter for increasing the success of structural \& formal PMSs over informal PMSs. This evidence gives hints of the direction to the users of informal PMSs, which kinds of KFs are most important and need firstly improvement for increasing the success of PMS.

Thus, almost all out of the fifteen questions associated with KSs indicate that the formal PMSs have a stronger link to KFs that the informal PMSs. Table 2 shows the mean, median, and standard deviation of the sum of the averages over the fifteen questions. The groups of formal PMSs have certainly higher means and lower standard deviations than the group of informal PMSs. These results indicate that the links to the chain of KFs are much stronger in the groups of formal PMSs. The samples of the three groups are not drawn from the same or identical distributions $(\mathrm{p}=0.0000)$. Thus, we can conclude that empirical evidence gives strong support to hypothesis 1 (H1).

\subsection{Impact on performance (hypothesis 2)}

Table 2 also presents descriptive statistics of the three performance measures and their sum variable for the three groups of PMS users. For the impact on the achievement of strategic objectives (STPER) the mean and median values are in the formal PMS groups higher than in the informal PMS group supporting hypothesis H2a. However, the differences between the groups are not statistically significant. The differences between the three groups are even smaller for the impact on nonfinancial performance (NFIPER). The means and medians are higher for the formal PMS groups than in the informal PMS group but again the differences are statistically insignificant ( $\mathrm{p}=0.6978$ ). Thus, only very weak support has been received for hypothesis $2 \mathrm{c}$.

It is, however, remarkable that for the impact of PMS on the financial performance (FINPER) the mean values in the formal PMS groups are respectively 4.43 and 4.15 when the mean is only 3.00 for the informal PMS group. Because the means of the impact on the achievement of strategic objectives and on nonfinancial performance are 4.2 and 4.0 in the informal PMS group respectively, we can conclude that an informal PMS may be inefficient in improving financial performance. At least, it is less efficient than a formal PMS. The differences between the groups of formality are statistically somewhat significant $(\mathrm{p}=0.0512)$. Therefore, our empirical evidence gives support to hypothesis $2 b$.

The differences in the mean impact on performance measures between the groups are shown in Figure 3. 
Table 1. Descriptive statistics of the fifteen check point measures

\begin{tabular}{|c|c|c|c|c|c|c|c|c|c|c|c|c|c|c|}
\hline & \multicolumn{4}{|c|}{ Structured \& formal PMSs $(n=23)$} & \multicolumn{4}{|c|}{ Formal PMSs $(n=34)$} & \multicolumn{3}{|c|}{ Informal PMSs $(n=5)$} & \multirow[b]{2}{*}{$\begin{array}{c}\% \text { of } \\
\text { zero } \\
\text { values } \\
\end{array}$} & \multirow[b]{2}{*}{ F-test } & \multirow[b]{2}{*}{ p-value } \\
\hline $\begin{array}{c}\text { Check point } \\
\text { (Variable) }\end{array}$ & Mean & Median & $\begin{array}{c}\text { Std. } \\
\text { Deviation } \\
\end{array}$ & $\begin{array}{c}\% \text { of } \\
\text { zero } \\
\text { values } \\
\end{array}$ & Mean & Median & $\begin{array}{c}\text { Std. } \\
\text { Deviation }\end{array}$ & $\begin{array}{c}\% \text { of } \\
\text { zero } \\
\text { values } \\
\end{array}$ & Mean & Median & $\begin{array}{c}\text { Std. } \\
\text { Deviation }\end{array}$ & & & \\
\hline MIS & 0,913 & 1,000 & 0,288 & 0,087 & 0,824 & 1,000 & 0,387 & 0,176 & 0,800 & 1,000 & 0,447 & 0,200 & 0,492 & 0,6137 \\
\hline STR & 0,957 & 1,000 & 0,209 & 0,043 & 0,765 & 1,000 & 0,431 & 0,235 & 0,400 & 0,000 & 0,548 & 0,600 & 5,003 & 0,0098 \\
\hline CSF & 0,478 & 0,000 & 0,511 & 0,522 & 0,324 & 0,000 & 0,475 & 0,676 & 0,000 & 0,000 & 0,000 & 1,000 & 2,268 & 0,1125 \\
\hline STROBJ & 0,957 & 1,000 & 0,209 & 0,043 & 0,647 & 1,000 & 0,485 & 0,353 & 0,400 & 0,000 & 0,548 & 0,600 & 5,797 & 0,0050 \\
\hline ORGKPI & 0,957 & 1,000 & 0,209 & 0,043 & 0,853 & 1,000 & 0,359 & 0,147 & 0,600 & 1,000 & 0,548 & 0,400 & 2,511 & 0,0899 \\
\hline UNOBJ & 0,870 & 1,000 & 0,344 & 0,130 & 0,853 & 1,000 & 0,359 & 0,147 & 0,200 & 0,000 & 0,447 & 0,800 & 7,704 & 0,0011 \\
\hline UNKPI & 0,957 & 1,000 & 0,209 & 0,043 & 0,824 & 1,000 & 0,387 & 0,176 & 0,400 & 0,000 & 0,548 & 0,600 & 5,359 & 0,0073 \\
\hline KPR & 1,000 & 1,000 & 0,000 & 0,000 & 0,706 & 1,000 & 0,462 & 0,294 & 0,600 & 1,000 & 0,548 & 0,400 & 5,067 & 0,0093 \\
\hline IMPUSE* & 0,601 & 0,667 & 0,265 & 0,000 & 0,603 & 0,667 & 0,253 & 0,088 & 0,367 & 0,500 & 0,342 & 0,400 & 1,828 & 0,1696 \\
\hline ACTUSE* & 0,652 & 0,667 & 0,166 & 0,000 & 0,647 & 0,667 & 0,224 & 0,029 & 0,267 & 0,167 & 0,303 & 0,400 & 7,556 & 0,0012 \\
\hline DNGUSE* & 0,674 & 0,667 & 0,163 & 0,000 & 0,667 & 0,667 & 0,205 & 0,029 & 0,267 & 0,167 & 0,303 & 0,400 & 9,427 & 0,0003 \\
\hline RESP* & 0,630 & 0,667 & 0,201 & 0,000 & 0,637 & 0,667 & 0,237 & 0,029 & 0,200 & 0,000 & 0,361 & 0,600 & 7,839 & 0,0010 \\
\hline INSYS & 0,957 & 1,000 & 0,209 & 0,043 & 0,824 & 1,000 & 0,387 & 0,176 & 0,400 & 0,000 & 0,548 & 0,600 & 5,359 & 0,0073 \\
\hline QUALINF* & 0,667 & 0,667 & 0,213 & 0,000 & 0,667 & 0,750 & 0,205 & 0,029 & 0,433 & 0,333 & 0,365 & 0,200 & 2,526 & 0,0886 \\
\hline ADJ & 0,783 & 1,000 & 0,422 & 0,217 & 0,794 & 1,000 & 0,410 & 0,206 & 0,400 & 0,000 & 0,548 & 0,600 & 1,933 & 0,1538 \\
\hline TOTAL & 12,051 & & & 1,171 & 10,632 & & & 2,790 & 5,733 & & & 7,800 & & \\
\hline
\end{tabular}

Legend:

For abbreviations see Appendix 3.

*: Standardized Likert scale between 0 and 1

Two-tailed p-values

Table 2. Descriptive statistics of PMS success measures and four research hypotheses

\begin{tabular}{|c|c|c|c|c|c|c|c|c|c|c|c|}
\hline & \multicolumn{3}{|c|}{ Structured \& formal PMSs $(n=23)$} & \multicolumn{3}{|c|}{ Formal PMSs $(n=34)$} & \multicolumn{3}{|c|}{ Informal PMSs $(\mathrm{n}=5)$} & \multirow[b]{2}{*}{ F-test } & \multirow[b]{2}{*}{ p-value } \\
\hline Variable & Mean & Median & Std. Deviation & Mean & Median & Std. Deviation & Mean & Median & Std. Deviation & & \\
\hline SUM (H1) & 12,051 & 12,667 & 1,38 & 10,632 & 11,500 & 2,95 & 5,733 & 4,000 & 4,94 & 11,398 & 0,0000 \\
\hline STPER (H2a) & 4,87 & 5,0 & 1,18 & 4,71 & 5,0 & 1,09 & 4,20 & 4,0 & 1,10 & 0,741 & 0,4809 \\
\hline FINPER $(\mathrm{H} 2 \mathrm{~b})$ & 4,43 & 4,0 & 1,20 & 4,15 & 4,0 & 1,13 & 3,00 & 3,0 & 1,22 & 3,127 & 0,0512 \\
\hline NFIPER $(\mathrm{H} 2 \mathrm{c})$ & 4,52 & 4,0 & 1,38 & 4,38 & 4,5 & 1,13 & 4,00 & 4,0 & 1,58 & 0,362 & 0,6978 \\
\hline Total (H2) & 13,83 & 13,0 & & 13,24 & 13,5 & & 11,20 & 11,0 & & & \\
\hline
\end{tabular}




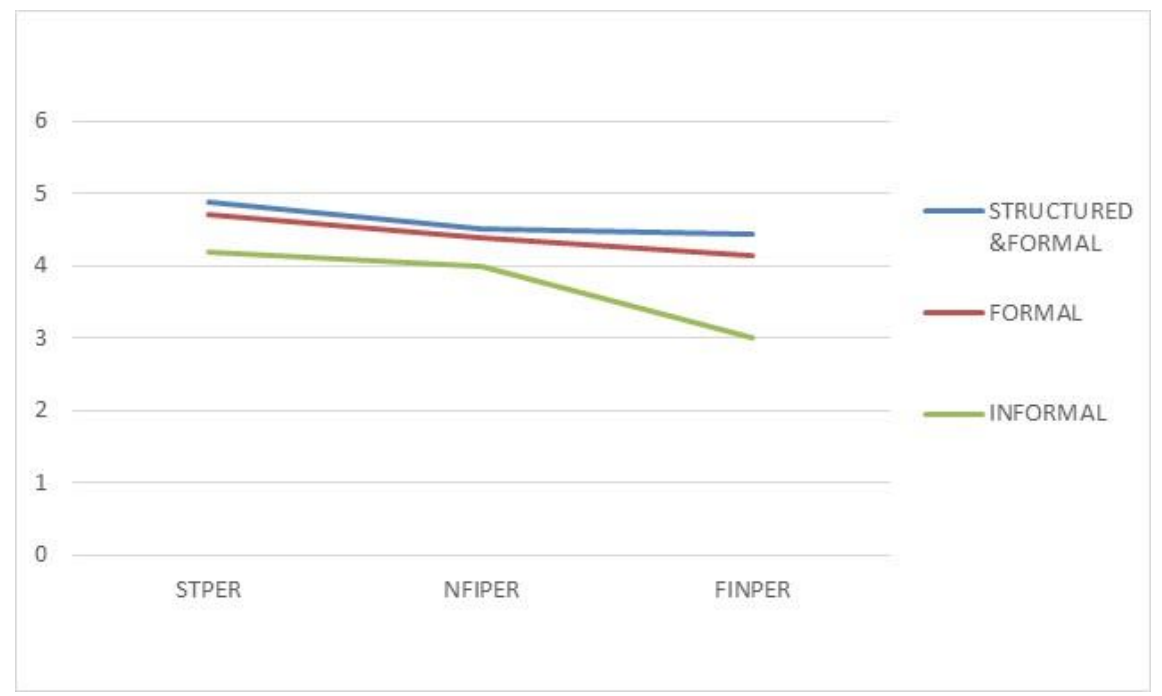

Figure 3. Mean values of performances for structured \& formal, formal and informal PMSs

\section{Conclusions of the study}

We can conclude that our empirical results supported strongly hypothesis H1. Therefore, we can conclude that the use of a structured \& formal well-known PMS leads to a stronger link to the chain of success KFs than the use of a formal in-house PMS and an informal PMS. Evidence also implies that in general the use of formal PMS results in a stronger link than the use of informal PMSs. We also found that the use of formal PMSs has a stronger impact on the achievement of strategic objectives $(\mathrm{H} 2 \mathrm{a})$ and nonfinancial performance $(\mathrm{H} 2 \mathrm{c})$ although the differences in the impact are not statistically significant.

We also investigated the impact of PMS on the financial performance. The impact of formality on financial performance in UK SMEs was investigated also by McKiernan and Morris (1994) who concluded that formality of planning systems has no impact on the financial performance. We received stronger statistically significant evidence to support $\mathrm{H} 2 \mathrm{~b}$ since the use of formal PMSs had a stronger positive impact on financial performance than the use of informal PMSs.

Furthermore, we analysed quantified similarities and differences between structural \& formal PMSs and informal PMSs. We found that both groups equally value the tails of PMS missions and the quality of provided information and also the systematic updating of PMSs. However, the differences between the groups indicated that the users of structural \& formal PMSs handle the strategy execution more in a more detailed way and the users of informal PMSs in a more complex way. The structural \& formal PMSs are also more closely associated with an incentive system than informal PMSs.

These findings provide a practical contribution giving to the informal PMSs hints of the direction, which kind of KFs matter most and need urgent improvement for increasing the success of PMS. Even small differences reflect the potential to increase the success of PMS for structural \& formal PMSs.

In general, empirical evidence emphasizes the advantages of the use of structured \& formal PMSs over other types of PMSs. Another important practical contribution of this paper is that this evidence encourages organizations to consciously enhance PMSs to make a stronger link to KFs, to move from informal PMSs to more formal PMSs and from in-house designed 
PMSs to the structured \& formal well-known PMSs which all lead to improvements in organizational performance.

The findings of this paper support the applicability of the chain model of KFs created by Kadak and Laitinen (2016). It seems to be a flexible framework to investigate the success of PMSs in different contexts. However, our analysis suffers from a small sample. The group of the users of informal PMSs only consisted of five organizations which made it very difficult to get statistically significant results. Therefore, future research should use larger samples to test the hypothesis. Finally, we used only a rough proxy to measure the formality of PMS. In future research, efforts should be made to use more advanced measures.

\section{Literature}

Abernethy, M. A., Chua, W. F. (1996). A Field Study of Control System "Redesign": The Impact of Institutional Processes on Strategic Choice. Contemporary Accounting Research, vol. 13, no. 2, pp. 569-606.

Anderson, S. W., Dekker, H. C. (2005). Management control for market transactions: the relation between transaction characteristics, incomplete contract design and subsequent performance. Management Science, vol. 51, no. 12, pp. 1734-1752

Anthony, R. N., Govindarajan, V. (2003). Management Control Systems. McGrawHill/Irwin

Beekes, W., Otley, D., Ururuka, V. (2010). The use and consequences of performance management and control systems: a study of a professional services firm", in CIMA, Research executive summary series. vol. 6, no. 10, pp. 1-6.

Bierbusse, P., Siesfeld, T. (1997). Measures that matter. Journal of Strategic Performance Measurement, vol. 1, pp. 6-11.

Bititci, U. S., Carrie, A. S., Mcdevitt, L. (1997). Integrated performance measurement systems: a development guide. International Journal of Operations \& Production Management, vol. 17, no. 5/6, pp. 522-534.

Braam, G. J. \& Nijssen, E. J. (2004) Performance effects of using the balanced scorecard: a note on the Dutch experience", Long Range Planning, vol. 37, 335-349

Bourne, M. (2005). Researching performance measurement system implementation: dynamics of success and failure. Production Planning and Control, vol. 16, no.2. March, 101-113

Bourne, M. C. S., Mills, J. F., Wilcox M., Neely A. D. \& Platts, K. W. (2000) "Designing, implementing and updating performance measurement systems. International Journal of Production and Operations Management, vol. 20, no. 7, pp. 754-771.

Bourne, M. C. S., Mills, J. F., Bicheno, J., Hamblin, D. J., Wilcox M., Neely, A. D., Platts, K. W. (1999). Performance measurement system design: testing a process approach in manufacturing companies. International Journal of Business Performance Measurement, vol. 1, no. 2.

Chapman, C. S. (1998). Accountants in organizational networks. Accounting, Organizations and Society, vol. 23. No. 8., pp. 737-766.

Chenhall, R. H., Hall, M., Smith, D. (2010). Social capital and management control systems: a study of a non-government organization. Accounting, Organizations and Society, vol. 35, no. 8 , pp. 737-756. 
Chenhall, R. H. (2003). Management control system design within its organizational context: findings from contingency-based research and directions for the future. Accounting, Organizations and Society, vol 28, no. (2-3), pp. 127-168.

Chenhall, R. H., Langfield-Smith, K. (1998). The relationship between strategic priorities, management techniques and management accounting: an empirical investigation using a systems approach. Accounting, Organizations and Society, vol. 23, no. 3, pp. 243-264.

Cokins, G. (2006). Case Studies in Performance Management: A Guide from the Experts. Wiley and SAS Business Series.

Daft, R. L., Macintosh, N. (1984). The Nature and Use of Formal Control and Strategy Implementation. Journal of Management, vol. 10 (Spring/Summer), pp. 43-66.

Davila, T. (2005). An exploratory study on the emergence of management control systems: formalizing human resources in small growing firms. Accounting, Organizations and Society, vol. 30, no. 3, pp. 223-248.

DeLone, W. H., McLean, E. R. (2003). The DeLone and McLean Model of Information Systems Success: A Ten-Year Update. Journal of Management Information Systems, vol. 19, no. 4, pp. 9-30.

Edis, M. (1995). Performance Management and Appraisal in Health Services. London: Kogan Page.

Ferreira, A., Otley, D. (2009). The Design and Use of Management Control Systems: An Extended Framework for Analysis. Management Accounting Research, vol. 20, pp. 263-282.

Garengo, P., Biazzo S., Bititci U. S. (2005). Performance measurement systems in SMEs: A review for a research agenda. International Journal of Management Reviews, vol. 7, no. 1, pp. $25-47$.

Globerson, S. (1985). Issues in developing a performance criteria system for an organization, International Journal of Production Research, vol. 23, pp. 639-646.

Kadak, T., Laitinen, E. K. (2016). What matters with PMS? Critical check points in the success of PMS. Studies in Managerial and Financial Accounting, Performance Measurement and Management Control: Contemporary Issues, vol. 31, pp. 111-140.

Kadak, T. (2011). Creation of a Supportive Model for Designing and Improving the Performance Management System of an Organisation. Case studies. Doctoral dissertation. Tallinn: Tallinn University of Technology.

Kaplan, R. S., Norton, D. P. (1996a). The Balanced Scorecard. Harvard: Harvard Business School Press.

Kaplan, R. S., Norton, D. P. (1996b). Using the Balanced Scorecard as a strategic management system. Harvard Business Review, vol. Jan-Feb, pp. 75- 85.

Kennerley, M., Neely, A. (2002). A framework of the factors affecting the evolution of performance measurement system. International Journal of Operations \& Production Management, vol. 22, no. 11, pp. 1223-1245.

Laitinen, E. K. (2004). Performance Measurement \& Management: Strategic View, University of Vaasa, Levon-institute. Strategic Management Accounting Research Unit. Publication no. 114. 
Langfield-Smith, K. \& Smith, D. (2003) "Management control systems and trust in outsourcing relationships", Management Accounting Research, vol. 14, no. 3, pp. 281-307.

Malmi, T., Brown D. A. (2008). Management control systems as a package - Opportunities, challenges and research directions. Management Accounting Research, vol. 19, no. 4, pp. 287-300.

McCunn, P. (1998) "The Balanced Scorecard: the Eleventh Commandment", Management Accounting, vol. 76, no. 11, pp. 34-36.

McKiernan, P., Morris, C. (1994). Strategic Planning and Financial Performance in UK SMEs: Does Formality Matter? British Journal of Management, vol 5. June, pp. 31-41.

Merchant, K. A. (1998). Modern Management Control Systems: Text and Cases, New Jersey: Prentice Hall.

Nanni, A. J., Dixon, J. R., Vollman, T. E. (1992). Integrated performance measurement: management accounting to support the new manufacturing realities. Journal of Management Accounting Research, vol. 4, pp. 1-19.

Najmi, M., Rigas, J., Fan, I. S. (2005) A framework to review performance measurement systems. Business Process Management Journal, vol. 11, no. 2, pp. 109-122.

Neely, A., Mills, J., Richards, H., Gregory, M., Bourne, J. \& Kennerley, M. (2000). Performance measurement system design: developing and testing a process-based approach. International Journal of Operations and Production Management, vol. 20, 1119-1145.

Neely, A. (1999). The Performance Measurement Revolution: Why now and what next? International Journal of Operations \& Production Management, vol. 19, no. 2, pp. 205-128

Olsen, E. O., Zhou, H., Lee, D. M. S., Chong, C. C, Ng, Y. N, Padunchwit, P. (2007). Performance Measurement System and Relationships with Performance Results. International Journal of Productivity and Performance Management, vol. 56, no. 7, pp. 559-582.

Ouchi, W. G., (1979). A conceptual framework for the design of organizational control mechanisms. Management Science, vol. 25, no. 9, pp. 833-848.

Perera, S, Harrison, G., Poole, M. (1997). Customer focused manufacturing strategy and the use of operations based non-financial performance measures: a research note. Accounting, Organizations and Society, vol. 22, no. 6 pp. 557-572. In Pock, T. (2007). Contingency-based Design of Management Control Systems Dissertation of the University of St. Gallen.

Rompho, N., Boon-itt, S. (2012). Measuring the success of a performance measurement system in Thai firms. International Journal of Productivity and Performance Management, vol. 61 , no. 5, pp. 548-562.

Sandelin, M. (2008). Operation of Management Control Practices as a Package - A Case Study on Control System Variety in a Growth Firm", Management Accounting Research, vol. 19, no. 4, pp. 324-343

Schneiderman, A. (1999). Why balanced scorecards fail. Journal of Strategic Performance Measurement, vol 6, Special edition, pp. 6-11

Simons, R. L. (2000). Performance measurement and control systems for implementing strategy. Upper Saddle River: Pearson.

Simons, R. L. (1995). Levers of control: how managers use innovative control systems to drive strategic renewal. Boston: Harvard Business School Press Books. 
Tangen, S. (2004). Evaluation and Revision of Performance Measurement Systems. Doctoral thesis. Stockholm: Woxe'n Centrum, Department of Production Engineering Royal Institute of Technology.

Tannenbaum, A. S. (1968). Control in Organizations. New York: McGraw-Hill

Tucker, B. P., Parker L. D. (2013). Out of control? Strategy in the NFP sector: the implications for management control. Accounting, Auditing \& Accountability Journal, vol. 26, no. 2, pp. 234-266

Qureshi, J. A, Shahjehan, A., Rehman, Z., Afsar, B. (2010). Performance management systems: A comparative analysis. African Journal of Business Management, vol. 4, no. 9, pp. $1856-1862$.

Verweire, K. \& Van den Berghe, L. (2004). Integrated Performance Management. A Guide to Strategy Implementation, London: Sage Publications

Wettstein, T. \& Kueng, P. (2002). A maturity model for performance measurement systems. In: Brebbia, C. A., Pascolo, P. (2002). Management Information Systems GIS and Remote Sensing. Southampton: WIT Press

Waal, A. A. (2007). Strategic Performance Management. A Managerial and Behavioural Approach. Palgrave: Macmillan.

Yu, L., Perera, S., Crowe, S. (2008). Effectiveness of the Balanced Scorecard: The Impact of Strategy and Causal Links. Journal of Applied Management Accounting Research, vol. 6, no. 2, pp. 37-55.

\section{Appendices}

\section{Appendix 1. Question about the type of PMS in use}

1. What kind of Performance Management System is your organization currently using?

a) Balanced Scorecard

b) Strategy Map

c) Any other well-known adopted system, please name it

d) System, designed by own

e) We do not use any

\section{Appendix 2. Questions about the 14 key factors (15 check points) of PMS}

1. MIS: Our organization has a stated mission (it is documented in a written form) (yes or no).

2. STR: Our organization has a document describing corporate strategy (it is documented in a written form) (yes or no).

3. CSF: Our organization's strategy document (map) includes descriptions of causal relationships between Critical Success Factors (CSFs) (yes or no).

4. STROBJ: Our corporate strategy document includes a description of corporate organization-level objectives (yes or no)

5. ORGKPI: Our corporate performance management system includes a set of organizationlevel performance measures (yes or no).

6. UNOBJ: Our organization has goals set on different hierarchical levels of the organization (yes or no). 
7. UNKPI: Our organization has a set of performance measures on different levels of organization (yes or no).

8. KPR: Our organization has defined key processes (yes or no).

9. IMPUSE: Our Performance Management System of Organization was built and designed with the users of this system (assess on a scale from $1=$ does not agree at all to $7=$ agree perfectly).

10.1. ACTUSE: Our Performance Management System of Organization is used interactively where managers are constantly and personally discussing with subordinates to learn strategic uncertainties and involved subordinates' decisions (assess on a scale from $1=$ does not agree at all to $7=$ agree perfectly).

10.2. DNGUSE: Our Performance Management System of Organization is used diagnostically where managers monitor organizational outcomes and correct deviations from present standards of performance (assess on a scale from $1=$ does not agree at all to $7=$ agree perfectly).

11. RESP: Our Performance Management System of Organization is intensively used by employees in charge (users of the system) (assess on a scale from $1=$ does not agree at all to 7 $=$ agree perfectly).

12. INSYS: Our Performance Management System of Organization is associated with an incentive system to motivate employees towards achievement of objectives (yes or no).

13. QUALINF: Our Performance Management System of Organization produces valid, reliable, timely and usable information for managerial work (assess on a scale from $1=$ does not agree at all to $7=$ agree perfectly).

14. ADJ: Our Performance Management System of Organization is systematically updated when changes in organization or environment are emerged (yes or no).

\section{Appendix 3. Questions about the impact of PMS}

1. STPER: How was the achievement rate of the latest strategic objectives assessed on a scale from 1 (extremely poor) to 7 (extremely good)?

2. NFIPER: How much do you consider the performance management system has improved the non-financial performance (productivity, efficiency, effectiveness) in the three last years on a scale from 1 (extremely little) to 7 (extremely much)?

3. FINPER: How much do you consider the performance management system has improved the financial performance (profitability, margins, turnover ratios) in the three last years on a scale from 1 (extremely little) to 7 (extremely much)? 